\title{
HISTORIA, ACCIÓN COLECTIVA Y RESPONSABILIDAD
}

\author{
Mariela Hemilse Acevedo
}

Universidad de Buenos Aires

\begin{abstract}
Resumen.- Pensar la relación de los hombres con la historia y la manera en que se posicionan desde un plano ético-político frente a ella -esto es, frente a la vida de los otros y frente a la vida con otros, sean ellos contemporáneos, sucesores o predecesores- nos remite tanto a las acciones como a las narraciones a partir de las cuales los hombres entrelazan sus vidas en un mundo en común. Considerando que las acciones políticas que los actores -individuales y colectivos- llevan a cabo en el presente se insertan en una determinada narración sobre la historia, es central comprender qué interpretación del pasado se anuda a la configuración identitaria de los distintos actores en tanto ésta opera como trama de sentido de sus acciones en el espacio público. Teniendo en cuenta estas consideraciones, en estas páginas el interés estará puesto en pensar algunas claves para abordar la responsabilidad que toda acción política supone asumir con la totalidad de la historia a partir de algunas nociones de Walter Benjamin y Paul Ricoeur.
\end{abstract}

Palabras clave.- historia, acción colectiva, responsabilidad, Walter Benjamin, Paul Ricoeur

Abstract.- Thinking about the relationship within men and history and how they position from an ethical-political aspect in front of it -that is, in front of the lives of others and in front of life with others, be they contemporaries or successors predecessors-, we refer both to the actions as narratives from which people connect their lives in a world in common. Whereas the policy actions that actors -individual and collective-, undertaken in the present are inserted into a particular narrative about the history, it is central to understanding why past performance is tied to the identity configuration of the different actors as it operates as a frame of meaning of their actions in public space. Given these considerations, this paper will be interest in thinking some clues to raise the responsibility that any political action supposes assuming with the totality of the history from some notions of Walter Benjamin and Paul Ricoeur.

Keywords: History, Collective Action, Responsibility, Walter Benjamin, Paul Ricoeur.

"Nuestra responsabilidad histórica es de esta manera primariamente responsabilidad por aquello que sucede y todavía sucederá; y es además la responsabilidad por aquello que sucede y sucederá con lo sucedido, así es en verdad responsabilidad moral y política, de la cual la historiografía no podrá desligarnos" ${ }^{11}$

\section{Introducción}

En estas páginas nos interesa reflexionar acerca de la responsabilidad histórica de la acción política. El punto de partida será considerar que las acciones políticas que los distintos actores -sean estos individuales o colectivos- llevan a cabo en el presente histórico se insertan en una determinada narración sobre la historia. De ahí que remarquemos en este planteo la necesidad de comprender

${ }^{1}$ (2005) SCHNÂDELBACH, Herbert, "¿Narrar historia o hacer historia? Otra vez acerca del sentido de la historia". En Cruz, Manuel y Brauer, Daniel (comps.), La comprensión del pasado. Escritos sobre filosofía de la historia, Editorial Herder, Barcelona, pág. 67. 
a qué interpretación del pasado se anuda la configuración identitaria de los actores en tanto ésta opera como trama de sentido de sus acciones en el espacio público. Así, se vuelve central para abordar la responsabilidad histórica de la acción política conocer a qué relato del pasado anuda su propia existencia un sujeto para comprender con quiénes asume responsabilidad en la historia a partir de su accionar político.

En lo que sigue, nos dedicaremos a señalar algunas claves para abordar estas cuestiones presentes en los planteos de Walter Benjamin y Paul Ricoeur. La propuesta es preguntarnos sobre la relación de los hombres con la historia, reflexionar acerca de nuestra condición de sujetos históricos y la manera en que nos configuramos históricamente.

La atención está puesta en el sujeto que vive, hace, sufre y narra la historia, cómo es su relación con el pasado, cómo se posiciona desde un plano éticopolítico frente a la historia -esto es, frente a la vida de los otros y frente a la vida con otros, sean ellos contemporáneos, sucesores o predecesores-. Y también la idea es considerar, por un lado, que la propia identidad del sujeto está signada por esa relación que guarda con la realidad histórica; y, por el otro, que la dimensión temporal de la experiencia humana implica pensar la historicidad de toda identidad.

Tanto en Benjamin como en Ricoeur encontramos aportes sumamente relevantes para mis reflexiones sobre estos temas, en particular teniendo en cuenta que en ambos autores la cuestión de la responsabilidad es central para pensar las acciones humanas situadas históricamente.

¿Por qué partir de la noción de historia de Walter Benjamin? La razón es que subyace allí una noción ético-política del conocimiento de la historia que exige reflexionar sobre las responsabilidades que le conciernen a cada uno en la historia -lo cual corre no sólo para los actores sociales sino también para los teóricos de lo social-. En Benjamin aparece una noción de historia que cuestiona la "historia oficial" que se construye sobre el silencio de los dominados -los dominados de ayer y de hoy- y que plantea una relación de redención y compromiso con el pasado que no pudo ser como manera de configurar un nuevo presente responsable de aquellos que sufren la historia oficial. De manera que sugiere tener en cuenta en qué pasado se reconoce el presente actual para que, a partir de allí, se pueda emprender una acción política que cuestione las injusticias del orden social imperante.

Por el lado de la teoría de Ricoeur, encontramos en el concepto de ipseidad o de "mantenimiento de sí" un punto de partida clave para considerar la dimensión ética de la identidad, esto es, la manera en que los sujetos se hacen responsables de sus actos ante los otros en la historia. Y ello se anuda al papel que le otorga a la narración en el proceso de constitución de la identidad, en tanto entiende que ésta se alcanza a partir de una operación de puesta en trama donde los acontecimientos que forman parte de la historia de un sujeto cobran sentido por la configuración de un relato. Entendida así, la identidad se piensa como devenir, como identidad que se despliega en el tiempo, y la 
narración es fundamental porque permite abordar la dimensión temporal de la experiencia humana -su historicidad-.

En definitiva, tomando como eje la noción de historia que plantea Benjamin y añadiendo a ello ciertas consideraciones sobre la noción de identidad narrativa de Ricoeur, pretendemos indicar algunas claves para abordar la responsabilidad que toda acción política supone asumir con la totalidad de la historia.

\section{El accionar político responsable en la historia como tiempo-ahora}

Partiendo de la idea de Agamben según la cual "cada concepción de la historia va siempre acompañada por una determinada experiencia del tiempo que está implícita en ella, que la condiciona y que precisamente se trata de esclarecer"2, comenzaremos indicando la crítica que realiza Benjamin en sus "Tesis de filosofía de la historia"3 a la concepción ideológica del tiempo implicada en la noción dominante de la historia como "linealidad continua y homogénea". En este sentido, será de interés central para examinar la relación entre el presente y el pasado su crítica a la noción de presente implicada en la concepción de la historia como continuum temporal: la idea de presente como plenitud visible y contemporánea a sí misma. Este cuestionamiento a la noción "vulgar" de la temporalidad histórica es el puntapié inicial para la producción benjaminiana de un nuevo concepto de tiempo histórico entendido como "tiempo-ahora", que parte de la idea de un presente no-contemporáneo, un presente complejo y configurado a partir de visibilidades e invisibilidades. Esta nueva concepción de la historia que plantea Benjamin supone asimismo una manera diferente de experimentar subjetivamente la historia que estaría en la base de un accionar político redentor o emancipador.

La edad moderna desarrolló una noción de tiempo "como continuum puntual, infinito y cuantificado" 4 . Esto es, sostuvo una noción de tiempo homogéneo, rectilíneo y vacío, pensado como mera sucesión de instantes en fuga, como simple cronología donde los acontecimientos se encadenan a partir de la lógica del "antes y después". Así, los sucesos históricos adquieren sentido al formar parte de este continuum cuyo movimiento rectilíneo y progresivo aparece como infinito.

De esta concepción objetiva y espacializada del tiempo resulta la naturalización de la historia como la secuencia visible de los acontecimientos empíricamente dados. Entendida la historia en estos términos, se admite una visión unitaria del acontecer histórico y una concepción de la realidad como fenómeno totalmente cognoscible. Así, apuntando a las visiones y las visibilidades que configura esta

\footnotetext{
2 (2001) AGAMBEN, Giorgio, Infancia e Historia, Adriana Hidalgo Editora, Buenos Aires, pág. 131.

${ }^{3}$ El título original del texto es "Sobre el concepto de historia", pero aquí citamos la versión que aparece en Discursos interrumpidos bajo la denominación "Tesis de filosofía de la historia". (1989) BENJAMIN, Walter, "Tesis de filosofía de la historia", en Discursos interrumpidos I: Filosofía del arte y de la historia, Taurus, Buenos Aires.

${ }^{4}$ (2001) AGAMBEN, Giorgio, op. cit., pág. 134.
} 
noción de historia, puede decirse que erige "Una" visión capaz de abarcar la totalidad de la historia y, como su contraparte lógica, una realidad plenamente visible y transparente. A ello se puede agregar que esta visión mantiene una relación neutra y contemplativa con la realidad -por eso naturaliza la historia y se extraña de ella-.

Dicho esto, la pregunta que surge sería la siguiente: ¿quién puede instituirse como poseedor de esta visión omnipotente? ¿Qué sujeto histórico podría ser la voz que construya un relato único de la historia? O, en los propios términos de Benjamin, ¿qué presente puede construir una relación de continuidad reconciliada con el pasado? ¿Qué escamotea este presente que arroja una mirada al pasado con la pretensión de iluminarlo en su totalidad y reconocerse en él como su continuidad? ¿Sobre qué silencios e invisibilidades se construye este continuum histórico?

El autor de las Tesis señalará que sólo el presente de la dominación puede pretender una relación de continuidad reconciliada con el pasado; y, en este sentido, denunciará que la continuidad de la historia requiere la intervención permanente de una "fuerza fuerte", es decir, de la fuerza social que domina en un momento histórico determinado y que legitima su dominación al reconocerse como pasaje natural del movimiento progresivo de la historia. Por ello su teoría cuestiona el tipo de relación que este presente de la historia "homogénea y vacía" guarda con el pasado, que difiere de la relación propuesta en su noción de historia como "tiempo-ahora". Dicho en otros términos, a la relación de dominación o de "salto de tigre" que el presente de la historia "homogénea y vacía" mantiene con el pasado, opondrá una relación de rescate y redención propia de la historia como "tiempo-ahora".

Tal como anticipamos, Walter Benjamin sostiene que la representación de la historia como continuidad lineal sólo puede ser producida por -y ser cómplice de- una fuerza que domina el presente y en el presente histórico ${ }^{5}$. Y esto es así porque se trata de un presente que se reconoce en sus partes visibles, en su identidad positiva, plena, sin fallas, y que reconoce en el pasado sólo aquello con lo cual se identifica. Sólo la "fuerza fuerte" del presente, sólo quien pretende la conservación del orden social vigente, recupera del pasado únicamente aquello que es la anticipación de sí mismo. Y esta, sin dudas, no es una operación ingenua ni genuina. Parafraseando a Marx ${ }^{6}$, es un presente que acude a los "ropajes del pasado" para "representar la nueva escena de la historia universal", y así, insertando su presente en el continuum de la historia, legitima su dominio en la tradición a la vez que olvida su carácter fallido (es decir, olvida las invisibilidades y los silencios -en fin, la historia muda de los vencidos- sobre los que funda su supuesta plenitud). Lo que se tiene, entonces, es un presente que se inserta en la "Historia Universal", que no es más que tránsito hacia un futuro de reconciliación que termina justificando el sacrificio

\footnotetext{
${ }^{5}$ Recordemos que, sin desconocer sus diferencias y especificidades, para Benjamin tanto el historicismo como el progresismo -incluso los de tinte marxista- y el fascismo sustentan esta idea de la historia como continuidad lineal, homogénea y vacía.

${ }^{6}$ (2000) MARX, Karl, El dieciocho Brumario de Luis Bonaparte, Siglo Veintidós Editora, Buenos Aires.
} 
sobre el que se funda todo orden social. Por eso es la manera de representar la historia propia de los "vencedores".

La crítica de Benjamin apunta entonces al "presente de identidad" o a la "ontología del presente". Esta última noción ha sido propuesta por Reyes Mate y retomada por Pablo Oyarzún Robles ${ }^{7}$ en su compilación de textos de Benjamin, y permite pensar al presente de la dominación como el imperio del "es", en tanto se trata de un presente que se hace coincidir consigo mismo. Pero, tal como indica Oyarzún Robles, "el predominio del presente no hace otra cosa que expresar la violencia de una dominación que busca coincidir consigo misma e hipostasiarse en el presente" ${ }^{\text {. }}$. Es decir, este presente pleno requiere la intervención permanente de una "fuerza fuerte" para constituirse y mantenerse como tal. Y esto es justamente lo que escamotea la ontología del presente en la medida en que niega el conflicto político insuprimible en el que se inscribe toda la historia $\mathrm{y}$, por lo tanto, niega el carácter trunco de todo presente al olvidar aquello que éste ha invisibilizado para poder "ser", y con ello, la violencia misma que está, así, en su origen.

Pero lo interesante del planteo benjaminiano es que señala un doble olvido que opera el presente de los vencedores. Este presente, identificándose con la historia visible de la dominación, borra no sólo su carácter trunco sino también el carácter trunco de un pasado "que no pudo ser" en su presente. Por eso el cuestionamiento a la concepción fetichista de un presente pleno se centra en el tipo de relación que guarda con el pasado. Por un lado, se trata de un presente que da un "salto de tigre" al pasado, figurando así la violencia que ejerce sobre el pasado al rescatar de él aquello que justifica su propia dominación. Por otro lado, este presente olvida un pasado truncado, del cual no se hace responsable. La pregunta que cabe hacerse, entonces, es por qué el presente desconoce este pasado trunco. Y la respuesta es que, al negar la violencia que hizo abortar las posibilidades que el pasado tuvo de realizarse en su presente, el presente niega el acto de violencia a partir del cual reduce a una voz las múltiples voces de lo social. En otras palabras, olvida el silenciamiento de las voces de los oprimidos a partir del cual se constituye como identidad plena. Y es por eso que la única voz que resuena en el relato de una historia unitaria es la voz de los vencedores.

De manera que es central para Benjamin que una noción materialista del tiempo histórico dé cuenta de este olvido sobre el cual se configura este presente pleno y elabore un concepto crítico de presente. Ya mencionamos que esta nueva concepción del presente remite a una nueva relación con el pasado. Basta indicar ahora que Benjamin se refiere específicamente a ese pasado trunco, a ese pasado pendiente con el cual el presente está en deuda y por el cual tiene que hacerse responsable.

7 (1996) OYARZÚN ROBLES, Pablo, "Cuatro señas sobre experiencia, historia y facticidad". En Benjamin, Walter, La dialéctica en suspenso. Fragmentos sobre historia (Traducción, introducción y notas de Pablo Oyarzún Robles), Ediciones ARCIS-LOM, Santiago de Chile, pág. 33-34.

(1996) OYARZÚN ROBLES, Pablo, op. cit., pág. 34. 
Es así como lo que está en juego en su teoría es la producción de un presente que introduzca una discontinuidad en la historia lineal de la dominación, que produzca una detención del tiempo pleno y vacío. Y esta detención del continuum de la historia se da a partir de la irrupción del pasado truncado en el presente pleno ideológico. Ello provoca el retorno fugaz del conflicto y se configura así un presente escindido, un presente no-contemporáneo y noreconciliado: el presente del "tiempo mesiánico" o "tiempo-ahora" benjaminiano es un presente que acoge a ese pasado pendiente, que lo reconoce y se responsabiliza por él; y al hacerlo, reconoce aquello pendiente que habita en el propio presente.

En este sentido, en la tesis XVI señala que "el materialista histórico no puede renunciar al concepto de un presente que no es transición, sino que ha llegado a detenerse en el tiempo"9. Y aquí queremos destacar una indicación que realiza Oyarzún Robles ${ }^{10}$ acerca del vocablo "einstehen" que usa Benjamin para hablar de un presente que "está fijo" o "detenido en el tiempo" ya que es central para lo que intentamos señalar acerca del accionar responsable en la historia. Oyarzún Robles menciona que este concepto también significa "ser responsable por algo", de manera que permite leer en esta tesis la indicación acerca de un presente que responde por las voces que han sido calladas en la historia, por ese pasado pendiente que reclama sentido.

Por eso puede decirse que Benjamin sugiere una noción de historia que es eminentemente ético-política ${ }^{11}$. Según nuestro entender, plantea un nuevo conocimiento histórico que remite tanto a los fundamentos de la historiografía materialista como a la manera particular en que los sujetos históricos (los oprimidos y aquellos comprometidos con su causa) se relacionan con la historia y con el pasado. Es decir, la idea de un conocimiento histórico redentor es tarea del materialista histórico pero también es la manera en que aquellos sujetos que padecen la dominación en el presente deben relacionarse con el pasado para abrir nuevas esperanzas de un futuro "de felicidad". Pero cabe aclarar que esta idea de un conocimiento redentor de la historia no supone que ese pasado pendiente pueda ser "subsanado" en el presente sino que, precisamente, es un conocimiento que rescata al pasado en tanto que pendiente, y lo redime al denunciar la injusticia que imposibilitó sus potencialidades de futuro.

Hasta aquí, intentamos demostrar cómo los dominadores de cada momento histórico cuentan con una determinada experiencia de la historia y una determinada narración acerca de ella que justifica su propia dominación. También mencionamos que una concepción de la historia como desenvolvimiento progresivo termina justificando las injusticias cometidas por un determinado orden social, cuestión que a nivel de la acción política de los individuos se traduce en una ausencia de responsabilidad en la historia. Asimismo, indicamos de qué manera determinadas filosofías de la historia sólo conocen la historia de los vencedores. En este sentido, nuestra exposición

\footnotetext{
9 (1989) BENJAMIN, Walter, op. cit., pág. 189.

${ }^{10}$ (1996) OYARZÚN ROBLES, Pablo, op. cit., pág. 63.

${ }^{11}$ Oyarzún Robles habla de una "epistemología política" de la historia en Benjamin. Ver (1996)

OYARZÚN ROBLES, Pablo, op. cit..
} 
coincide con Oyarzún Robles en considerar que "tanto el progresismo como el historicismo consagran, como conocimiento histórico, no el recuerdo, sino el olvido, y al hacerlo, sellan su complicidad, voluntaria o no, con los dominadores"12.

Resta ahora explicitar con más detenimiento cuáles son las implicancias de este conocimiento redentor de la historia tanto para el que hace "historia" -la disciplina- como para el que vive, actúa y sufre (en) la historia.

En primer lugar, y en lo que respecta a la tarea del materialista histórico, el autor de las Tesis indica que éste debe "pasar el cepillo a contrapelo a la historia" para hacer visible el horror que se esconde en la historia de los vencedores. Es decir -partiendo de la idea de que todo instante trae consigo su "chance revolucionaria", es decir, que en la realidad objetiva permanentemente hay resquicios desde donde puede aflorar el conflicto opacado- la tarea del materialista histórico es leer (entiéndase, producir críticamente) en el "presente de identidad" el retorno fugaz de esa escisión / no-plenitud olvidada que convierte al presente contemporáneo en "presente saturado". De manera que la crítica que el materialista histórico ejerce sobre el presente pleno es ella misma una práctica política, en tanto que es un pensamiento comprometido con aquellos que sufren las injusticias de un orden social.

En segundo lugar, si consideramos las implicancias que puede tener la idea de un conocimiento redentor de la historia en el accionar de los sujetos que sufren las opresiones del presente, puede leerse en la teoría de la historia de Benjamin la alusión a una nueva relación entre la acción y la historia, a una nueva subjetividad histórica que esté ética y políticamente comprometida con el cuestionamiento del orden vigente, y donde el recuerdo cobra un papel fundamental para la construcción de la identidad de los sujetos que actúan en la historia. En referencia a las potencialidades del recuerdo, resulta interesante retomar una lectura de Benjamin que realiza Antonio Aguilera que va en la dirección de lo que estamos señalando aquí:

"Para que aflore el recuerdo ${ }^{13}$, el futuro del pasado no cumplido, se necesita de la fuerza adecuada, de memoria y de inteligencia, de una atención a lo presente. Recordar no es algo que pertenezca al pasado, sino que es un acto bien Ileno de vida presente. Eso es lo primero que olvidan los particularismos que invocan un pasado siempre idéntico, en la pretendida normalización de lo que no es idéntico, precisamente en el ahora. El recuerdo mítico invoca en la hora de lo ya cumplido algo pasado que ya ha dejado de estar oprimido. Se usa la memoria histórica, incluso de lo maltratado ya pasado, para aplastar lo presente maltratado, en una identificación con los vencedores de la historia. Bajo la apariencia de una memoria histórica de lo no cumplido emerge la voracidad de un presente que aplasta, que encorseta lo vivo. Los intereses económicos y políticos que han adquirido fuerza inventan un pasado mítico. Benjamin apela

12 (1996) OYARZÚN ROBLES, Pablo, op. cit., pág. 41. Las cursivas son nuestras.

${ }^{13}$ También Oyarzún Robles habla de la función histórica del recuerdo en un conocimiento del pasado que se pretender redentor de éste. Ver (1996) OYARZÚN ROBLES, Pablo, op. cit.. 
a una relación entre lo oprimido presente y lo no cumplido pasado en vistas a un futuro distinto, no al recuerdo de los vencedores" ${ }^{14}$.

El recuerdo recuperaría, entonces, ese pasado pendiente que reclama sentido. $Y$ se trata de un pasado que reclama sentido porque Benjamin encuentra el sentido de la historia no en el futuro sino en el pasado, en ese sentido no cumplido por el que debería responder el accionar político en el presente. A lo cual agrega el autor recién citado:

"Encontrar sentido es conectar líneas que enlazan un pasado con la encrucijada presente. Ni es mera cronología ni evolución, es un relámpago que ilumina posibilidades actuales. El pasado arranca su carga desde la insatisfacción presente, algo ciega, eleva la mirada teórica hasta una constelación pasada que pudo ser de otra manera y la desplaza hacia el porvenir. Del presente frustrado hacia el pasado no cumplido y susceptible de cumplimiento, hacia el futuro pasado que contrasta con el futuro de este presente" ${ }^{\prime 15}$.

Todo esto también puede pensarse en términos de constitución de una tradición, de la necesidad de construir una determinada narrativa que organice la relación con los predecesores (dominados) bajo la idea de "compromiso", que orientaría la práctica política que se lleva a cabo en el presente. Benjamin habla de una "cita secreta" entre generaciones: "existe una cita secreta entre las generaciones que fueron y la nuestra. Y como cada generación que vivió antes que nosotros, nos ha sido dada una flaca fuerza mesiánica sobre la que el pasado exige derechos"16.

Y para pensar estas cuestiones consideramos que es pertinente introducir algunas consideraciones de la teoría de Ricoeur acerca de la constitución narrativa de la identidad. Repasando brevemente la conceptualización sobre la identidad que realiza en su libro "Sí mismo como otro"17, es preciso indicar que allí presenta dos maneras de pensar la identidad, una a partir de la noción de mismidad (que, en relación a la cuestión de la identidad colectiva que trato en mi trabajo de tesis, estaría refiriendo a la idea de rasgos comunes, permanencia empírica y sustancia) y otra a partir de la noción de ipseidad (que remite a la idea de atestación o mantenimiento de la palabra dada, es decir, se relaciona con las nociones de intención, decisión, voto, promesa, pacto) ${ }^{18}$. La tarea de la identidad narrativa es llevar a cabo la dialéctica de la mismidadipseidad. En otros términos, a partir de una operación de "puesta en trama", la narración de sí que hace el sujeto permite incorporar el devenir constante de su

\footnotetext{
${ }^{14}$ (2002) AGUILERA, Antonio, "Huellas, marcas, indicios: las voces silenciadas (variación sobre el concepto de historia en Benjamin)". En Cruz, Manuel (comp.) Hacia dónde va el pasado. El porvenir de la memoria en el mundo contemporáneo, Editorial Paidós, Barcelona, pág. 105106. Las cursivas son nuestras.

${ }^{15}$ (2002) AGUILERA, Antonio, op. cit., pág. 109. Las cursivas son nuestras.

${ }^{16}$ (1989) BENJAMIN, Walter, op. cit., pág. 178.

17 (1995) RICOEUR, Paul, Sí mismo como otro, FCE, Buenos Aires.

${ }^{18}$ Ver (2004) NAISHTAT, Francisco, Problemas filosóficos en la acción individual y colectiva: una perspectiva pragmática, Prometeo Libros, Buenos Aires, pág. 377 y siguientes.
} 
identidad que se despliega en el tiempo en la unidad identitaria que se configura narrativamente ${ }^{19}$. Este relato está dando cuenta del quién de la acción, del sujeto que se responsabiliza por la acción ante los otros. Y aquí aparece la dimensión ética de la identidad, según la cual toda acción inscripta en la historia supone un "hacerse disponible para el otro", un hacerse responsable de las consecuencias que conlleva la propia acción para la historia. Y lo interesante es considerar que la temporalidad de la trama no es la del tiempo lineal, es la del encadenamiento de hechos significativos para la configuración del relato, de la historia de la identidad del sujeto colectivo. Y aquí aparece la idea de una interpretación narrativa del pasado; del pasado de la vida de ese actor colectivo particular pero también del pasado compartido con los otros.

Por otro lado, y como aspecto importante para pensar el accionar político de los actores, hay que tener en cuenta que este relato sirve de marco interpretativo a las acciones que se planean y se llevan a cabo. Esta íntima relación entre acción-reflexión-narración lleva a concebir a la identidad no como a priori de la acción sino como una reconfiguración que va sucediendo con el acontecer de la acción.

Por otra parte, también habrá que considerar la manera en que este relato acerca de la identidad de un sujeto colectivo se inscribe en un determinado macro-relato de la historia. Con ello queremos decir que a partir de una trama narrativa que configure los acontecimientos históricos de una determinada manera, se entenderá cómo el actor colectivo concatena su existencia con la vida de sus predecesores, sus contemporáneos y sus sucesores. Sólo así se podrá saber a qué pasado y a qué futuro estaría anudando su responsabilidad histórica. Retomando la referencia a Benjamin, será vital entender cuál es su interpretación narrativa del pasado, es decir, a qué relato del pasado anuda su propia existencia, para comprender con quiénes asume compromisos en la historia en cada una de sus acciones públicas.

\section{Palabras finales}

Si la historia no es mera cronología; si, por el contrario, es posible elaborar nuevas narrativas de la historia que otorguen a los acontecimientos del pasado un sentido diferente al que les da la historia de los vencedores, habrá que pensar entonces qué tramas de sentido sobre el acontecer histórico sitúan a la responsabilidad histórica -tanto para con el pasado como para con el futuro- en el centro de la reflexión sobre las acciones políticas que se llevan a cabo en el presente. Esto, entendemos, estaría en consonancia con un conocimiento redentor de la historia y con una manera ética de actuar en la historia.

19 (1999) RICOEUR, Paul, "La identidad narrativa", en Historia y narratividad, Paidós, Barcelona. 


\section{Bibliografía:}

-(2001) AGAMBEN, Giorgio, Infancia e Historia, Adriana Hidalgo Editora, Buenos Aires.

-(2002) AGUILERA, Antonio, "Huellas, marcas, indicios: las voces silenciadas (variación sobre el concepto de historia en Benjamin)". En Cruz, Manuel (comp.) Hacia dónde va el pasado. El porvenir de la memoria en el mundo contemporáneo, Editorial Paidós, Barcelona.

-(1989) BENJAMIN, Walter, "Tesis de filosofía de la historia", en Discursos interrumpidos I: Filosofía del arte y de la historia, Taurus, Buenos Aires.

-(2004) CANCLINI, Néstor, Diferentes, desiguales y desconectados. Mapas de la interculturalidad, Editorial Gedisa, Barcelona.

-(2003) CATANZARO, Gisela, “¿Por qué la historia y no más bien la Nada? Notas sobre el problema del tiempo y la causalidad". En Catanzaro, Gisela e Ipar, Ezequiel, Las aventuras del marxismo, Editorial Gorla, Buenos Aires.

-(2000) MARX, Karl, El dieciocho Brumario de Luis Bonaparte, Siglo Veintidós Editora, Buenos Aires.

-(2004) NAISHTAT, Francisco, Problemas filosóficos en la acción individual y colectiva: una perspectiva pragmática, Prometeo Libros, Buenos Aires.

-(1996) OYARZÚN ROBLES, Pablo, "Cuatro señas sobre experiencia, historia y facticidad". En Benjamin, Walter, La dialéctica en suspenso. Fragmentos sobre historia (Traducción, introducción y notas de Pablo Oyarzún Robles), Ediciones ARCIS-LOM, Santiago de Chile.

-(1995) RICOEUR, Paul, Sí mismo como otro, FCE, Buenos Aires.

-(1999) RICOEUR, Paul, "La identidad narrativa", en Historia y narratividad, Paidós, Barcelona.

-(2005) SCHNÂDELBACH, Herbert, “¿Narrar historia o hacer historia? Otra vez acerca del sentido de la historia". En Cruz, Manuel y Brauer, Daniel (comps.), La comprensión del pasado. Escritos sobre filosofía de la historia, Editorial Herder, Barcelona. 